\title{
FORMAÇÃO DE PROFESSORES E TRABALHO DOCENTE NA EDUCAÇÃO INFANTIL: 0 QUE AS PESQUISAS REVELAM?
}

\author{
Lívia Bernardes Rodrigues, Evanileide Patrícia Lima Figueira, Renata Portela Rinaldi \\ Universidade Estadual Paulista - UNESP, Programa de Pós-Graduação em Educação, Presidente Prudente, SP. E-mail: \\ livia.bernardes.rodrigues@gmail.com
}

\begin{abstract}
RESUMO
A Educação Infantil teve uma grande expansão na última década. No campo quantitativo, no que diz respeito ao acesso, não se pode negar; mas qual a qualidade desse acesso? Quem é o profissional em exercício nesse nível de ensino na atualidade? Partindo de tais questionamentos, a presente produção, que se vincula a uma investigação mais ampla sobre a formação de professores e o trabalho docente nos diferentes níveis de ensino, tem como objetivo mapear a produção científica acerca da temática "formação de professores e trabalho docente na Educação Infantil" por meio de pesquisa bibliográfica em dois periódicos conceituados no campo da educação, a saber: Revista Brasileira de Educação e Caderno CEDES, entre 2000 a 2016. Pode-se observar que a produção científica na área é escassa, o que sugere desinteresse por esse nível de ensino ou um silenciamento para as questões da formação e do trabalho docente na educação infantil.

Palavras-chave: formação de professores, trabalho docente, educação infantil.
\end{abstract}

\section{TEACHER FORMATION AND TEACHING WORK IN CHILDREN'S EDUCATION: WHAT DOES THE RESEARCH SHOW?}

\begin{abstract}
Children's Education is an area that has grown a lot in the last decade. In the quantitative field, in regard to access, that cannot be denied; but what is the quality of this access? Who is the professional currently working in this level of education? Based on these questions, this project, which is part of a broader investigation on teacher training and teaching work on different levels, aimed to gather scientific production on the theme "teacher's formation and teaching work in Children's Education" through bibliographical research in two renowned journals of the area of education: Revista Brasileira de Educação and Caderno CEDES, between 2000 and 2016. Scientific production in the area is still scarce, which suggests a lack of interest in this level of education or a silencing of matters of formation and teaching work in children's education.
\end{abstract}

Keywords: teacher's formation, teaching work, children's education. 


\section{INTRODUÇÃO}

Historicamente, a criação das escolas para crianças pequenas, deixou marcas perceptíveis na sociedade até a atualidade. Sendo considerada, por muito tempo, a extensão do lar - o "segundo lar" - sua função ficou estagnada na atenção básica às crianças pouco se questionando O que? Como? Por quê? Quem? está por trás dos processos que aconteciam no interior dessas instituições. Assim, emergiram ao longo da história, estereótipos acerca do papel social da escola fazendo com que recaísse sobre o educador a função assistencial. Neste cenário foi sendo tecida a imagem social da escola e do professor destinados a atender este nível de ensino. Imagem essa que trouxe resultados perversos na construção do perfil profissional, principalmente, do professor que atua com crianças e que se arrasta até os dias de hoje (ARCE, 2008).

Paralelo a tais acontecimentos, a concepção de criança e infância foi assumindo novos significados; se (re)significou. De simples seres biológicos (ARIÈS, 1981) a sujeitos produtores de culturas - suas próprias culturas (SARMENTO, 2013), as crianças se tornam, na contemporaneidade, sujeitos capazes de protagonizar sua própria história (SARMENTO, 2004). A partir disso, a maneira como se percebe a infância muda. Novas percepções trazem novos olhares; e, à luz desses novos olhares, essa fase da vida passa a assumir um lugar próprio na sociedade. Nesse momento, emerge questionamentos acerca do papel da escola e do professor que passam a ocupar lugar nessa "nova criança", nessa "nova infância". Embora a construção da identidade dos professores e instituições tenha sido construída num cenário de desvalorização, no momento em que a infância é (re)significada, se repensa também nos sujeitos e locais que acolherão as crianças pequenas. Assim, é natural que essas mudanças apontem para a necessidade da tomada de decisões no que tange a Educação Infantil - seja ela na figura do professor e da própria escola.

Concomitante às ressignificações surgidas no campo da infância percebe-se um movimento no cenário político, ainda que tímido, em direção à Educação. Assim, em 1996 foi aprovada a Lei no 9.394 (BRASIL, 1996), que estabeleceu as Diretrizes e Bases da Educação Nacional no país. Entretanto, na ocasião de sua aprovação, a Educação Infantil fica à mercê, uma vez que, ao dispor sobre a obrigatoriedade do ensino, o documento coloca que o ensino obrigatório e gratuito tem seu início no ensino fundamental, não estando a etapa pré-escolar no escopo deste documento. Passados três anos, em 1999, mais um avanço é obtido no campo das políticas públicas no que tange a Educação. Por meio do Decreto no 3.276 (BRASIL, 1999) os professores, para atuar na Educação Básica, deverão, preferencialmente, ter formação em nível superior - um ganho para a área da Educação, mas com pouco significado para o campo da Educação Infantil, uma vez que este nível de ensino, na ocisão, ainda não estava contemplado na Educação Básica.

Assim, com o intuito de oferecer maior apoio aos grupos sociais em desvantagem, o Ministério da Educação - MEC - tenta conciliar as políticas dirigidas a todos - universais - sem requisito de seleção. Propõe, então, a ampliação da obrigatoriedade escolar para a faixa etária dos 4 aos 17 anos e, desse modo, a Educação Básica passa a ser compreendida como: Educação Infantil - pré-escola -, Ensino Fundamental e Ensino Médio (BRASIL, 2006a). Ainda em 2006, é autorizado pela Lei no 11.273 (BRASIL, 2006b) a concessão de bolsas de estudo e de pesquisa aos participantes de programa de formação inicial e continuada de professores para a educação básica.

Percebe-se, então, a preocupação crescente com a qualidade da educação. Então, em 2007 é proposto pelo governo federal o Plano de Metas Compromisso Todos pela Educação, por meio do Decreto no 6.094, de 24 de abril de 2007 em regime de colaboração com Municípios, Distrito Federal e Estados, e a participação das famílias e da comunidade, mediante programas e ações de assistência técnica e financeira, visando a mobilização social pela melhoria da qualidade da educação básica (BRASIL, 2007). Por fim, em 2008 estabelece-se o piso salarial nacional para os profissionais do magistério público da Educação Básica, Lei no 11.738, de 16 de julho de 2008 (BRASIL, 2008). 
A referida contextualização nos permite concluir, no que diz respeito a evolução teórica no campo das políticas públicas de Educação, que houve um ganho. Entretanto, nos indagamos sobre o que efetivamente está em prática especialmente na Educação Infantil? A partir disso, o objetivo desta produção, que se articula a uma investigação mais ampla sobre a formação de professores e o trabalho docente nos diferentes níveis de ensino foi elucidar o que as pesquisas na área de trabalho docente e formação de professores na educação infantil têm a nos dizer ao longo dos últimos 16 anos.

\section{METODOLOGIA}

Partindo de um levantamento bibliográfico, a metodologia empregada na presente pesquisa se caracteriza como uma pesquisa bibliográfica. Severino (1941), descreve esse tipo de pesquisa como sendo aquela "[...[ que se realiza a partir do registro disponível, decorrente de pesquisas anteriores, em documentos impressos, como livros, artigos[...] O pesquisador trabalha a partir das contribuições dos autores dos estudos analíticos constantes no texto" (SEVERINO, 2007, p. 122). Vale salientar que, a relevância da metodologia empregada está no planejamento cuidadoso, com critérios rigorosamente definidos, que orientará a busca aprofundada dos estudos realizados acerca da temática que se propõe a investigar. É a partir desse aprofundamento que emergem possibilidades, por exemplo, de "[...] mapear a área, traçar um panorama das principais tendências teóricas-metodológicas de investigação, discutir resultados e apontar tanto avanços e conquistas quanto as (muitas) lacunas ainda existentes" (KRAMER, 1996, p. 27).

Assim, compreender a temática que se propõe pesquisar por meio dos achados científicos acerca dela própria, justifica-se pelo fato de que, quer no plano real, quer no ideal, o que dá forma ao desempenho docente são os movimentos políticos, econômicos e socioculturais; a pesquisa acompanha-os (CUNHA, 2013).

Para a realização da coleta de dados, foram selecionados dois periódicos muito relevantes da área da educação, a saber: Revista Brasileira de Educação (RBE) e Caderno CEDES. Foram definidos o período do levantamento dos dados entre 2000 a 2016 e os seguintes descritores: formação de professores, educação infantil e trabalho docente.

As estratégias utilizadas para a realização das buscas nos dois periódicos se difere por conta das características de sua organização. A Revista Brasileira de Educação disponibiliza em sua base de dados campos para que a busca aconteça por meio do emprego de palavras-chave e foi realizado da seguinte forma: Formação de Professores, Educação Infantil, Trabalho Docente. Inicialmente os termos foram utilizados de maneira isolada; após a primeira busca, utilizou-se os termos cruzados - Formação de Professores and Educação Infantil, Trabalho Docente and Educação Infantil. Já o Caderno CEDES, está organizado em exemplares, sendo que as buscas se dão por meio de acesso a cada título, individualmente. Após, acesso, por meio de leitura de títulos, análise de resumos e textos completos, o trabalho é selecionado caso esteja dentro da temática na qual a presente pesquisa pretende se aprofundar.

O procedimento de análise pauta-se numa perspectiva descritivo-analítica em que inicialmente, após seleção dos textos e a leitura de todos os resumos são reorganizados e separados para análise aqueles que abordam o tema objeto de estudo, os resultados desse processo são depurados a partir da leitura na íntegra de todo o material e os resultados apresentados a seguir.

\section{RESULTADOS}

Os resultados obtidos na Revista Brasileira de Educação (RBE) estão descritos na Tabela 1. De modo geral é possível observar que as temáticas mais abrangentes [formação de professores ou educação infantil ou trabalho docente], quando pesquisadas isoladamente apontam para um maior número de artigos publicados. Verifica-se que a temática trabalho docente, nos periódicos 
investigados, receberam pouca atenção por parte dos pesquisadores. Ainda, quando combinados os temas e o nível de ensino [Educação infantil] os resultados são mais escassos e preocupantes.

Tabela 1. Resultados da busca por descritores no período de 2000 a 2016 Periódico Consultado: Revista Brasileira de Educação

\begin{tabular}{l|c|c}
\hline \multicolumn{1}{c|}{ Palavras-chave } & Trabalhos Consultados & Trabalhos Selecionados \\
\hline Formação de Professores & 31 & 2 \\
\hline Educação Infantil & 12 & 2 \\
\hline Formação de Professores and Educação Infantil & 1 & 0 \\
\hline Trabalho Docente & 5 & 1 \\
\hline Trabalho Docente and Educação Infantil & 1 & 0 \\
\hline Total & 50 & 5 \\
\hline
\end{tabular}

Fonte: Sistematizado pelas autoras a partir do mapeamento nas bases de dados da RBE.

Após o mapeamento inicial realizado por descritor, realizou-se a contagem do número de publicações totais por ano de publicação ao longo do período, a fim de analisar frequência relativa em que se produzem artigos com o tema (Tabela 2 ).

Tabela 2. Frequência Relativa acerca da Temática na RBE

\begin{tabular}{c|c|c|c}
\hline Ano & $\begin{array}{c}\text { Total de } \\
\text { Publicações }\end{array}$ & $\begin{array}{c}\text { Publicações } \\
\text { no tema }\end{array}$ & $\begin{array}{c}\text { Frequência } \\
\text { Relativa (\%) }\end{array}$ \\
\hline 2000 & 16 & 0 & 0,0 \\
\hline 2001 & 26 & 0 & 0,0 \\
\hline 2002 & 27 & 0 & 0,0 \\
\hline 2003 & 30 & 0 & 0,0 \\
\hline 2004 & 33 & 0 & 0,0 \\
\hline 2005 & 30 & 0 & 0,0 \\
\hline 2006 & 34 & 0 & 0,0 \\
\hline 2007 & 31 & 0 & 0,0 \\
\hline 2008 & 34 & 0 & 0,0 \\
\hline 2009 & 30 & 1 & 3,3 \\
\hline 2010 & 32 & 0 & 0,0 \\
\hline 2011 & 29 & 0 & 0,0 \\
\hline 2012 & 29 & 2 & 6,9 \\
\hline 2013 & 42 & 0 & 0,0 \\
\hline 2014 & 45 & 1 & 2,2 \\
\hline 2015 & 43 & 1 & 2,3 \\
\hline 2016 & 42 & 0 & 0,0 \\
\hline
\end{tabular}

Fonte: Sistematizado pelas autoras a partir do mapeamento nas bases de dados da RBE.

Por sua vez, os resultados obtidos no Caderno CEDES se encontram descritos na Tabela 3, em que é possível visualizar também a frequência com que trabalhos dentro da temática proposta pela presente pesquisa comparecem ao longo dos anos.

Tabela 3. Frequência Relativa acerca da Temática no Caderno CEDES 


\begin{tabular}{c|c|c|c}
\hline Ano & $\begin{array}{c}\text { Total de } \\
\text { Publicações }\end{array}$ & $\begin{array}{c}\text { Publicações } \\
\text { no tema }\end{array}$ & $\begin{array}{c}\text { Frequência } \\
\text { Relativa } \\
\text { (\%) }\end{array}$ \\
\hline 2000 & 21 & 0 & 0,0 \\
\hline 2001 & 18 & 0 & 0,0 \\
\hline 2002 & 16 & 0 & 0,0 \\
\hline 2003 & 23 & 0 & 0,0 \\
\hline 2004 & 18 & 0 & 0,0 \\
\hline 2005 & 21 & 0 & 0,0 \\
\hline 2006 & 18 & 0 & 0,0 \\
\hline 2007 & 16 & 0 & 0,0 \\
\hline 2008 & 17 & 1 & 5,9 \\
\hline 2009 & 22 & 0 & 0,0 \\
\hline 2010 & 21 & 1 & 4,8 \\
\hline 2011 & 18 & 0 & 0,0 \\
\hline 2012 & 20 & 0 & 0,0 \\
\hline 2013 & 18 & 0 & 0,0 \\
\hline 2014 & 19 & 0 & 0,0 \\
\hline 2015 & 25 & 4 & 16,0 \\
\hline 2016 & 21 & 1 & 4,8 \\
\hline
\end{tabular}

Fonte: Sistematizado pelas autoras a partir do mapeamento nas bases de dados do caderno CEDES.

Os resultados descritos na Tabela 3, de modo geral evidenciam que, dentro da temática analisada, há poucos trabalhos publicados - apenas sete trabalhos em um total de 332 publicações ao longo do período (2000 a 2016). Constata-se que a representatividade da temática explorada neste artigo é de apenas $2,1 \%$, fato que evidencia o desinteresse da academia e/ou o silenciamento da temática neste nível de ensino.

\section{DISCUSSÃO}

A análise apresentada nos resultados evidencia uma baixa produção científica nos últimos dezessete anos acerca da temática "Formação de Professores e Trabalho Docente na Educação Infantil" nos periódicos investigados. Tal fato é corroborado ao confrontarmos o total de publicações nos dois periódicos analisados - RBE e Caderno CEDES - frente às produções acerca da temática - 885 artigos foram publicados, sendo que destes apenas $12(1,36 \%)$ tratam do assunto.

A partir de tais dados, observa-se que a temática, ao longo do tempo, tem sido pouco investigada nos veículos analisados, sugerindo um desinteresse pelo assunto, bem como um silenciamento em relação a temática da formação e do trabalho docente, no primeiro nível que compõe a educação básica que é a Educação Infantil. Tais achados nos remetem a indagações outras para compreender tal fenômeno, por exemplo: a escassez de produções pode estar relacionada ao escopo dos periódicos? Em quais veículos comunidades de pesquisadores que investigam sobre a Educação Infantil têm utilizado para veicular suas produções? Quais temáticas têm sido priorizadas por eles? A ampliação do estudo requer atenção para esses novos questionamentos.

\section{CONCLUSÃO}

Sabe-se hoje que a infância tem papel fundamental no desenvolvimento do ser. Com isso, observa-se um movimento político e social no campo teórico a esse respeito. Entretanto, no que 
diz respeito às práticas no interior das escolas envolvendo os professores deste nível de ensino no campo da formação e do trabalho docente - as pesquisas evidenciam poucos avanços e até mesmo um silenciamento da temática. Dessa maneira, no campo da prática, muito tem que se avançar na Educação Infantil a fim de que este nível de ensino cumpra seu papel: trabalhar com as potencialidades da criança a fim de que seu desenvolvimento seja pleno, seja integral.

\section{REFERÊNCIAS}

ARCE, A. O MOBRAL e a educação de crianças menores de seis anos durante o regime militar: em defesa do trabalho voluntário. Cad. CEDES, v. 28, n. 76, p. 379-403, set./dez. 2008, https://doi.org/10.1590/S0101$\underline{32622008000300006}$.

ARIÈS, P. História social da criança e da família. In: A descoberta da infância. 2. ed. Rio de Janeiro: LTC, 1981. p.17-31.

BRASIL, 1996. Casa Civil da Presidência da República. Lei de Diretrizes e Bases da Educação Nacional. Brasília: Casa Civil da Presidência, 1996. Brasília: Casa Civil da Presidência da República, 1996. Disponível em: http://www.planalto.gov.br/ccivil 03/leis/L9394.htm. Acesso em: 31 jul. 2017.

BRASIL, 1999. Casa Civil da Presidência da República. Decreto no 3.276, de 6 de dezembro de 1999. Dispõe sobre a formação em nível superior de professores para atuar na educação básica, e dá outras providências. Brasília: Casa Civil da Presidência da República, 1999. Disponível em: < http://www.planalto.gov.br/ccivil 03/decreto/d3276.htm>. Acesso em: 31 jul. 2017.

BRASIL, 2006a. Casa Civil da Presidência da República. Lei no 11.274, de 6 de fevereiro de 2006. Altera a redação dos arts. 29, 30, 32 e 87 da Lei no 9.394, de 20 de dezembro de 1996. Brasília: Casa Civil da Presidência da República, 2006a. Disponível em: http://www.planalto.gov.br/ccivil 03/Ato20042006/2006/Lei/L11274.htm. Acesso em: 31 jul. 2017.

BRASIL, 2006b. Casa Civil da Presidência. Lei no 11.273, de 6 de fevereiro de 2006. Brasília: Casa Civil da Presidência da República, 2006b. Disponível em: http://www.planalto.gov.br/ccivil 03/Ato20042006/2006/Lei/L11273.htm. Acesso em: 31 jul. 2017.

BRASIL, 2007. Casa Civil da Presidência da República. Decreto no 6.094, de 24 de abril de 2007. Brasília: Casa Civil da Presidência da República, 2007. Disponível em: http://www.planalto.gov.br/ccivil 03/ Ato2007-2010/2007/Decreto/D6094.htm. Acesso em: 01 ago. 2017. BRASIL, 2008. Casa Civil da Presidência da República. Lei no 11.738, de 16 de julho de 2008. Brasília: Casa Civil da Presidência da República, 2008. Disponível em: < http://www.planalto.gov.br/ccivil 03/ Ato20072010/2008/Lei/L11738.htm>. Acesso em: 01 ago. 2017.

CUNHA, M. I. O tema da formação de professores: trajetórias e tendências do campo na pesquisa e na ação. Educação e Pesquisa, São Paulo, v.39, n.3, p.609-625, jul./set.2013. Disponível em: <http://www.scielo.br/pdf/ep/v39n3/aop1096.pdf>. Acesso em: 11 jun. 2017.

KRAMER, S. Pesquisando infância e educação: um encontro com Walter Benjamin. In: KRAMER, S; LEITE, M. I. (Orgs). Infância: fios e desafios da pesquisa. Campinas: Papirus, 1996.

SARMENTO, M.J. As culturas da infância nas encruzilhadas da segunda modernidade. In: ; CERISARA, A.B. Crianças e Miúdos: perspectivas sociopedagógicas da infância e educação. Porto, Portugal: Asa Editores, 2004.

SARMENTO, M.J. A emergência da sociologia da infância em Portugal. Revista Educação: Cultura e Sociologia da Infância. ed.1, 2013. p. 14-27. Disponível em: www.editorasegmento.com.br. Acesso em: 03 fev. 2017. 
SEVERINO, A. J. Metodologia do Trabalho Científico. - 23. ed. rev. e atual. - São Paulo: Cortez, 2007. 